\title{
Alfonso IX y sus relaciones con Castilla $^{1}$
}

\author{
JOSÉ-LUIS MARTIN *
}

Tras los exhaustivos trabajos de Julio González sobre los reinados de Fernando II y de Alfonso IX de León, de Altonso VIII de Castilla y de Fernando III de Castilla y León, poco puede añadirse sobre las relaciones entre León y Castilla durante los años de ruptura, entre la muerte del Emperador Alfonso VII -1157- y la unificación de los reinos por Fernando III en 1230. Es posible, sin embargo, matizar algunos aspectos de las relaciones entre León y Castilla y, sobre todo, conocer la opinión de los contemporáneos, leyendo con detención las bien conocidas crónicas de Rodrigo Jiménez de Rada y de Lucas de Tuy, rigurosamente contemporáneos del castellano Alfonso VIII y del leonés Alfonso IX, y de los menos conocidos textos del franciscano Juan Gil, autor, hacia 1283, de una biografía del Alfonxo IX de León", Ninguno de los autores es sospechoso de

\section{* UNED}

Este articulo es una version. ligeramente modificada, de la conferencia pronunciada en Sarriá (Lugo) con motivo de la celebración de los ochocientos años de la fundación de la villa por Alfonso IX, fallecido en este lugar

Sobre la vida y obra de Juan Gil, puede verse el estudio de Costas. Jenaro. Juan Gil. Alabanzas e Historia de Zamora. Zamora 1994.

El texto latino de la biografia de Alfonso IX, procedente de la Biblioteca Nacional, codice 1, 217. fls. 71 v. -73 v.. fue publicado en 1883 por FITA, Fidel, "Biografia inedita de Alfonso IX, rey de León, por Gil de Zamora". Boletin Real Academia de la Historia. 13, págs. 291-295

En la introducción al texto. Fita recuerda que en esta biografia asi como en las de Fernando !II y Alfonso $X$. Juan Gil sigue, y a veces copia literalmente, los textos del Toledano y del Tudense pero anadiendo por su parte datos originales. que no poco interesan a la Historia. Por lo que se reiiere a la presente biografía Fita recuerda que "los numeros 1, 2, 5, 7, 10 y 11 corresponden. si bien ampliados y mejorados, a la obra maestra del arzobispo D. Rodrigo" -De rebus Hispaniae. lib. VII. capitulos 24 y 25- "asi como los mismos y los restantes a la del Tudense" - SCHOTT. Hispania Illustrata, tomo IV , págs. 108-115, Francfort 1603--- "más o menos abreviado".

Aunque los textos son conocidos. los reproduzco en apéndice para que el lector pueda ver los puntos de vista castellano y leonés a la hora de presentar al mismo personaje. incluso cuando como ocurre en el caso de Juan Gil se sirve de las obras del Toledano y del Tudense. 
oponerse a la unión de los reinos y los tres pueden ser considerados cronistas aúlicos u oficiales: Rodrigo dedica su obra a! serenissimo, invicto et semper augusto domino suo Fernando, Dei gratia regi Castellae et Toleti, Legionis et Gallaeciae, Cordubae atque Murciae ${ }^{3}$, es decir a Fernando III, hijo de Alfonxo IX y de Berenguela, reina para la que escribe Lucas de Tuy: astrictis praeceptis gloriosissimae ac prudentissimae Hispaniarum Reginae dominae Berengariae, quae ut chronicorum libros... sibi scriberem imperavit hanc praemisi praefationem... '. Por su parte, Juan Gil dedica el Liber de preconiis Hispanie al serenissimo domino suo Infanti Sancio, Illustrissimi Aldefonsi regis Legionis et Castelle. Tholeti ac Vandalie maiori filio et heredi... ${ }^{5}$ y a pesar de todo, sus textos nos los presentan como claramente partidarios de Castilla - Rodrigo Jiménez de Rada- o como defensores del leonés Alfonso IX, según puede verse en los textos agrupados alrededor de tres puntos: personalidad e inicio del reinado de Alfonso, paces y guerras con Castilla, y sucesión de Alfonso-unificación castellanoleonesa.

\section{LA PERSONALIDAD DE ALFONSO IX}

El primer dato que llama la atención es el espacio que uno y otro cronista dedican al personaje, a Alfonso IX: si la extensión fuera signo de inclinación hacia Castilla o León, podriamos afirmar que Rodrigo Jiménez de Rada adopta una postura claramente castellanista y en pocas lineas resume el reinado de Alfonso IX sobre el que vuelve, indirectamente, cuando habla del monarca castellano; la proporción se invierte si consideramos la crónica de Lucas de Tuy; la extensión dedicada al personaje no es, como puede observar el lector, la única diferencia entre los relatos de Rodrigo Jiménez de Rada, por un lado, y Lucas de Tuy o Juan Gil, personaje al que podemos tildar de leonesista si tenemos en cuenta cómo enjuicia en la crónica de Zamora el asedio de la ciudad por el castellano Sancho II y cómo justifica la defensa llevada a cabo

Deberia incluirse entre las crónicas que se ocupan de Altonso IX la Crónica escrita por o en el circulo de Altonso $X$. pero sigue literalmente y de manera exclusiva a Rodrigo Jiménez de Rada por lo que poco anade a lo que este dice y si tiene algún interés habrá que buscarlo en la traducción al castellano del texto del arzobispo toledano.

Pag. 1 de la edición de Cabant S. M. Desamparados, Rodericus Ximenius de Rada. Opera. Valencia 1968.

Pag. 1 de la edición de Schort.

Pag. 3 de la edición de Casiko. Manuel de. Fray Juan Gil de Zamora. O. F. M De preconirs Hispanie Madrid 1955 
por Urraca y la intervención de Vellido Dolfos "; aquí, Juan Gil acentúa las alabanzas y omite o niega abiertamente los que él considera aspectos negativos de la actuación de Alfonso IX. Asi, por ejemplo, Jiménez de Rada define al rey leonés como "hombre piadoso, valiente y benigno aunque se dejaba influir por los malos consejeros"; Lucas de Tuy lo presenta como "hermoso, elocuente, clemente, fuerte físicamente y hábil en el uso de las armas y fiel católico " en un caso, y en otro recuerda que "en la guerra jamás fue vencido y siempre salió vencedor cuantas veces combatió a cristianos o a musulmanes" para acabar, con el Toledano, aludiendo a su debilidad ante los chismosos, convertida aqui en virtud: temperalmente violento ${ }^{8}$ podia pasar fácilmente de la ira extrema - «su voz cuando estaba airado se parecia al rugido del león»-- a la clemencia y olvidar las insinuaciones "si había quien dijese algo bueno"; a estas virtudes hay que añadir el amor a la justicia y el odio a los delincuentes: para evitar que los jueces se dejaran corromper les prohibió percibir cualquier cantidad o aceptar regalos por administrar justicia y les pagaba de su propio tesoro, y a clos ladrones y soberbios los hacia despeñar desde las torres más altas o los mandaba ahogar en el mar, colgaba a otros, quemaba a algunos, los hacia cocer en calderas, les arrancaba la piel en vivo y los afligía con los tormenos más diversos para mantener el reino en paz y justicia".

Juan Gil toma de uno y de otro lo que más favorece al monarca y añade nuevos calificativos no exentos de interés: con Jiménez de Rada considera a Alfonso "piadoso, valiente y benigno" y con Lucas e Tuy "hermoso, elocuente" ", amante de la justicia, controlador de los jueces, y siempre vencedor en la guerra con un matiz importante pues venció siempre "sin la ayuda de gentes extrañas", frase con la que sin duda pretende negar la colaboración de Alfonso IX con los musulmanes, mencionada por el arzobispo toledano ". El valor militar de Alfonso IX Ilega, para Juan Gil,

Sobre este punto véase la presentación de 893-1993 en su dia mi trabajo "Vellido Dolfos. ¿traidor o caballero enamorado?". en Zamora. 1.100 anos de historia. Zamora, 1995.

Fue misericordioso con los clérigos hasta el punto de facilitarles alimentos de sus propios cilleros cuando lo necesitaban y distribuia entre los monasterios el ganado conseguido como botin en la guerra

Vestido con las armas de guerra y montado a caballo. su gesto denotaba extraordinaria ferocidad.

A estos adjetivos añade los de "sencillo". "alegre". "magnánimo" y "liberal".

El término "extrañas" puede aplicarse también a castellanos, portugueses o aragoneses en cuyo caso el adjetivo serviria para reforzar la independencia leonesa. Aunque Juan Gil escribe cincuenta años despues de la unión de leoneses y castellanos. todavia en esta época se mantienen las diferencias entre ambos reinos. diferencias que llevan, por ejemplo, a Sancho IV a convocar separadamente las Cortes de Castilla y las de León y a éstas a pedir que solo puedan ser jueces los naturales de cada reino. o deciden a Lucas de Tuy o Juan Gil a hacer intervenir a San isidoro de León en los combates con los musulmanes al lado de Santiago en lugar del castellano San Millán cantado en estos mismos años por Gonzalo de Berceo. 
a extremos demagógicos: en los últimos años de su vida, Alfonso IX se enfrenta a Ibn Hud, vencedor de los almohades y unificador de los reinos musulmanes de la Península, y cuando se prepara para entrar en combate pierde una de las espuelas, hecho que es interpretado por todos como un mal presagio; por todos menos por Alfonso que explica el hecho no como un accidente negativo sino como una decisión positiva: "el rey no debe entrar en combate con espuelas como los miedosos y por esto cayó la espuela, para animarme a quitar también la otra" demostrando así que no pensaba huir - difícilmente podría cabalgar sin espuelas- sino perseverar en el combate.

Los comienzos del reinado. Desde las primeras líneas, recuerda el arzobispo toledano que Alfonso IX aceptó convertirse en "vasallo" caballeresco del rey de Castilla para librarse de los ataques conjuntos de castellanos y portugueses; con este objetivo se presentó el leonés en la curia de Carrión y allí recibió de Alfonso VIII el cíngulo de caballero y besó las manos del castellano en presencia de todos, gesto que sus aduladores cortesanos le presentarán como humillante "y del que se vengará buscando la alianza del monarca portugués contra Castilla; asi explica Rodrigo el matrimonio de Alfonso IX con Teresa de Portugal: "Este contubernio -Alfonso y Teresa eran parientes en segundo grado- fue acordado por odio al rey de Castilla pues inficionado por sus cortesanos, se dolía Alfonso de haber recibido el cíngulo caballeresco de manos del rey de Castilla". Juan Gil sigue al pie de la letra la versión del arzobispo toledano incluso cuando indica que en la misma curia fue armado caballero por Alfonso VIII Conrado, hijo del emperador de Alemania, al que fue dada como esposa Berenguela, hija mayor del monarca de Castilla. La unión de ambas noticias no se debe sólo a la coincidencia en el tiempo de las dos ceremonias caballerescas sino al interés de Rodrigo por llamar la atención sobre la actitud de Berenguela, que se opuso con todas sus fuerzas al matrimonio hasta conseguir que éste fuera anulado; aunque no lo diga expresamente, el arzobispo sugiere que Berenguela estaba decidida a casarse con Alfonso de

El estado de ánimo de Alfonso IX será definido años más tarde por el autor de Las Mocedades de Rodrigo cuando pone en boca del Cid los siguientes versos:

Allegó don Diego Lainez

al rey besar la mano.

Quando esto vio Rodrigo

non le quiso besar la mano..

Porque vos la bessó mi padre

soy mal amanzellado...

(ed. de Devermono. A. D. Epic poetry and the clergy. Studies on the "Mocedades de Rodrigo" Londres 1969, pág. 243). 
León para llevar la paz a los reinos cristianos: "la joven Berenguela permaneció soltera y asi por este tiempo se pacificó la tierra..." hasta que influido por sus consejeros Alfonso IX se unió a Teresa de Portugal.

Nada señala Lucas de Tuy sobre la caballería recibida por Alfonso IX en Carrión, y se limita a indicar que cante los ataques de su consobrino Alfonso, rey de Castilla, fue llevado a casarse con Teresa... para tener la ayuda del rey Sancho de Portugal contra Alfonso". El silencio y la justificación del Tudense, que tendremos ocasión de observar cada vez que algo puede ir contra el buen nombre de Alfonso, se debe sin duda a la negativa consciente o inconsciente a aceptar la dependencia leonesa que implica ser armado caballero su rey por el castellano y, sobre todo, al deseo de salvar la honra de Alfonso, puesta en entredicho por sus guerras contra Castilla pues «establescieron los antiguos que el cavallero nunca fuesse contra aquél de quien oviesse recibido cavallería... E otrosí non ha de ser en fecho, nin en consejo de ninguna cosa que su daño fuesse, mas á lo destorvar quanto podiere, que non sea ${ }^{12} \mathrm{~m} \ldots$

\section{GUERRA Y PAZ CON CASTILLA}

En un artículo como éste, no es posible ni merece la pena referirnos a las continuas guerras, paces, treguas y alianzas establecidas entre los distintos reinos hispánicos, cristianos y musulmanes, por lo que dejamos de lado cualquier referencia militar para centrarnos en tres puntos de interés: la justificación o condena de las alianzas, la creación del Estudio Salmantino, dependiente como su iglesia de la archidiócesis compostelana, y la estrecha relación de ésta con la actual Extremadura, discutida por musulmanes, portugueses, castellanos y leoneses hasta que estos últimos se imponen en tiempo de Alfonso IX y se consolida el traslado de la archidiócesis de Mérida a Santiago, sede que tendrá en tierras extremeñas el arcedianato de Reina, sobre cuya existencia e interés llamó mi atención la tesis doctoral, de Francisco Javier Pérez Rodríguez sobre El Cabildo de Santiago de Compostela (siglos XII-XV) ${ }^{13}$.

Buenos y malos consejeros, inteligencia y arrojo. En los párrafos dedicados a Alfonso IX, el arzobispo toledano se limita a mencionar paces y

\footnotetext{
Partida Segunda, titulo XXI (Las Siete Partidas, glosadas por el Licenciado Gregorio Lopez. Salamanca 1555 , reedición de 1985).

1995.
} 
guerras sin culpabilizar ni justificar a ninguno de los reyes, pero sí a los consejeros de Alfonso IX a los que responsabiliza del matrimonio con Teresa de Portugal para borrar la humillación que suponia haber sido armado caballero por el castellano ${ }^{14}$, pero cuando traza la historia de Alfonso VIII de Castilla, Rodrigo Jiménez de Rada siempre carga las culpas sobre el monarca leonés: "el castellano siempre fue atacado por su primo" a pesar de que él sólo se ocupaba de sus asuntos y para nada interferia en el reino leonés; con motivo de la batalla de Alarcos, el leonés y con él el monarca navarro "simularon" ir en auxilio del castellano pero no movieron un dedo para ayudarlo frente a los musulmanes, y aprovecharon la derrota castellana para "entrar hostilmente en el reino de Castilla», y el leonés no tuvo inconveniente en "firmar un tratado con los musulmanes e incorporar tropas árabes a sus ejércitos para ocupar los Campos Góticos destruyendo, talando, devastando..."; la provocación fue contestada por Alfonso VIII mediante una alianza con Pedro el Católico de Aragón que mantuvo alejado al rey de Navarra y permitió que el castellano ocupara diversas plazas fuertes en el reino leonés, no sin antes firmar una tregua con los musulmanes "para poder enfrentarse con mayores garantias a los reyes convecinos". Mientras el leonés firma "tratados" e incorpora musulmanes a su ejército, el castellano se limita a una "tregua", a cuya firma se ve obligado por quienes le atacan, es decir por León y Navarra.

La presión militar y el temor a nuevos daños obliga al leonés a pedir la paz y la mano de Berenguela, que le fue concedida junto con las tierras y castillos ocupados. Sigue al matrimonio un periodo de colaboración contra Navarra y contra los musulmanes: si en el primer caso Castilla sale beneficiada por tener fronteras con Navarra, en el segundo León consigue el apoyo de tropas castellanas con cuya colaboración ocupa la plaza fuerte de Alcántara que, más tarde, sería entregada a la orden de Calatrava; sin duda, la anulación canónica del matrimonio de Alfonso y Berenguela llevó a nuevos entrentamientos que podrían explicar la ausencia de Alfonso IX y de sus guerreros en Las Navas de Tolosa.

Si Juan Gil ha negado de entrada cualquier colaboracion de Alfonso IX con los musulmanes, el Tudense se centra en rechazar la acusación de no haber querido intervenir en Alarcos y en justificar la ausencia en Las Navas de las tropas leonesas; respecto a la primera ocasión, Alfonso "acudió con un gran ejército pero el castellano, ansioso por entrar en

Por sugerencia de los serviles que le rodeaban se dolia de haber recibido el cingulo caballeresco.. 
combate, no pudo esperar su llegada aunque ya Alfonso estaba en las proximidades de Toledo". Ante el enfrentamiento con el miramamolín, el castellano pidió la colaboración de aragoneses y navarros, que acudieron, y de los leoneses cuyo rey deseaba colaborar pero, tras reunir su consejo, "respondió que con gusto iría si el monarca castellano le devolvia los castillos que le había ocupado"; ante la falta de respuesta, el leonés no se presentó en Las Navas y aprovechó las dificultades de su oponente para recuperar las plazas fuertes y ocupar otras en Castilla mientras otros ejércitos penetraban en Portugal y se apoderaban de diversos lugares. La victoria suavizó el temperamento de Alfonso VIII quien lejos de tomar venganza medió entre Portugal y León para conseguir que todos juntos y en paz se centraran en la guerra contra los musulmanes.

El cielo no permaneció, según Lucas de Tuy al que sigue Juan Gil, ajeno a estas guerras fratricidas entre leoneses y castellanos y se manifestó en la iglesia de San Esteban, extramuros de León: “una imagen de la Virgen con el Niño lloró lágrimas de sangre y provocó la afluencia de numerosos fieles y clérigos que trasladaron la imagen a San Isidoro donde durante tres dias Madre e Hijo lloraron sangre, según algunos sabios que interpretaron el fenómeno, como señal y predicción de la guerra que vendría..., interpretación cuya veracidad mostraron los hechos posteriores».

El "leonesismo" de Lucas de Tuy no le impide reconocer la superioridad del entorno del monarca castellano, rodeado de sabios consejeros gracias a los cuales sobresalió por encima de los demás reyes hispanos, mientras Alfonso IX se rodeaba de clérigos que cantaban armoniosamente los oficios divinos, y de "cubicularios" laicos con los que consultaba todos sus hechos, y aunque el monarca actuaba con gran honradez, en ocasiones prestaba oidos a las maledicencias y se portaba de forma no conveniente a un rey, criterios que no comparte $u$ omite Juan Gil para quien Alfonso tuvo siempre la ayuda divina frente a todos sus vecinos, especialmente desde el momento en que fundó el Estudio salmantino: para impetrar un mayor auxilio divino, creó a su propia costa el Estudio General de Salamanca; y desde entonces tuvo en sus manos más directamente la victoria, en la que de nuevo colabora el cielo con prodigios que narran tanto Lucas de Tuy como Juan Gil y de los que nos ocuparemos al hablar de la archidiócesis de Mérida-Santiago de Compostela.

Mérida-Santiago y Toledo. Las relaciones castellano leonesas tienen un campo privilegiado de actuación en el mundo eclesiástico, politizado como no podia ser menos desde el momento en que se produce la división de los reinos. La habilidad y las buenas relaciones de Diego Gelmírez con Roma y con Alfonso VII le permitieron, en 1120, trasladar a Santiago 
la archidiócesis de Mérida hasta que fuese reconquistada la ciudad a los musulmanes; cuatro años más tarde. Calixto II confirmaba la traslación con un cambio importante: "la dignidad que habiamos concedido hasta que la ciudad de Mérida fuera devuelta a los cristianos, la confirmamos para siempre de forma que la en otro tiempo famosisima y opulentísima ciudad emeritense... permanezca por siempre sometida a la ciudad de Compostela como su metrópoli... Los obispos sufragáneos de Mérida, los de Salamanca. Ávila y Coimbra y los demás que en otro tiempo se sabe han estado sometidos a Mérida, presten obediencia como a su metropolitano al arzobispo compostelano». Los arzobispos de Toledo y Braga vieron, sin duda, con recelo la intromisión compostelana en zonas sometidas a su influencia, pero mientras Castilla y León permanecieron unidas y Portugal fue un condado del reino, el problema no salió del ámbito eclesiástico "y sólo cuando hacia 1140 Portugal se independiza y en 1157 se separan León y Castilia, las diferencias eclesiásticas adquieren un fuerte matiz politico: la continuidad de la archidiócesis de Santiago depende más que nunca del control físico de la ciudad de Mérida, aspiración manifestada por Gelmírez al conseguir en 1129 que Alfonso VII le hiciera donación de la ciudad; tras separarse los reinos, los sucesores de Gelmirez obtuvieron de Fernando II en 1170 y de Alfonso IX en 1229 la confirmación del privilegio del Emperador, la concesión de la ciudad de Mérida ".

Los privilegios reales eran importantes perc sólo válidos si la ciudad era conquistada por e! rey leonés, y desde 1160, la zona extremeña es disputada a los musulmanes y a León por castellanos y portugueses o, si se prefiere, eclesiásticamente por Braga y Toledo. Los intereses del rey de León coinciden en este punto pleriamente con los del arzobispo compostelano y si en 1170 Fernando II confirma la donación de Mérida, un año más tarde el arzobispo pone los medios para hacer efectiva la conquista, ocupación y control al firmar un pacto de familiaritas con la recién creada orden militar de Cáceres que pronto cambiará su nombre por el de Santiago ": el arzobispo Pedro II, de acuerdo con sus canónigos, recibe al maestre Pedro

Toledo reacciono pidiendo a Roma que anulara la concesion. intervino en el nombramiento del obispo salmantino. pidio a Braga y Coimbra que no reconocieran las atribuciones de Diego Gelmure... (Historia Compostellana. II. LXV LXVIII. págs. 356-365. de la edición de Emma Falque Rey. 1988)

Informacion mas detaliada sobre este aspecto puede verse en la tesis doctoral de PERH. Francisco Javier. El cabildo de Santiago de Compostela (siglos xit-xiv)

Sobre la presion castellana y portuguesa en Extremadura -aqui adquirio su sobrenombre de el Cid portugues Geraldo Sempavor-veanse las paginas que dedico al tema en Origenes de la Orden de Santiago. Barcelona 1974. pags. 3-10. 
Fernández y a sus sucesores como "canónigos" de la iglesia de Santiago y a los freires como "vasallos y caballeros" del Apóstol para que en adelante luchen por Cristo "bajo la bandera de Santiago, para honra de su iglesia» y ampliación de la fe. Por su parte, el arzobispo se ofrece y es admitido, él y quienes le sucedan, entre los freires.

El pacto se convierte en acuerdo militar cuando el arzobispo se compromete a dar consejo y ayuda armada, personalmente y con sus vasallos y caballeros, a la Orden, y si ocurriera que el arzobispo no pudiera acudir personalmente al llamamiento del rey, sus hombres se pondrian bajo las órdenes del maestre y combatirian con los freires. A la ayuda militar se une la económica: la mitad de los votos de Santiago procedentes de las diócesis de Zamora, Salamanca y Ciudad Rodrigo y la totalidad de los votos de Ávila y de la Transierra, la mitad de Alburquerque y de sus términos, la cuarta parte de la ciudad de Mérida con una de las mejores capillas y con la mitad de los derechos reales otorgados por Fernando II, y la luctuosa de los caballeros de Tierra de Santiago. La donación está condicionada a que los freires ocupen y mantengan Alburquerque, y a elia se añade la mitad de los frutos de las heredades y de los derechos de la sede en Zamora, Salamanca y Ledesma, que conservarán los freires hasta que la frontera musulmana se aleje de Alburquerque, Cáceres y Mérida, hasta que los derechos de Santiago estén claramente consolidados en Extremadura.

Los éxitos santiaguistas en esta zona fueron de corta duración y durante años los almohades recuperaron el control de Extremadura, donde Castilla funda la ciudad y crea el obispado de Plasencia "cuya posesión podía cortar el paso hacia el sur de los ejércitos leoneses y poner en peligro los derechos de la iglesia de Santiago que veia establecer entre "sus" sedes de Salamanca, Ciudad Rodrigo y Mérida la recién creada sede "toledana" de Plasencia; tal vez, Alfonso IX no participó en la batalla de Las Navas por temor a que una victoria castellana podria traducirse en la ocupación de Extremadura, a cuya conquista dedicó el rey leonés los mayores esfuerzos tras la muerte de Altonso VIII de Castilla según recuerda Lucas de Tuy: en una primera campaña saquea la comarca de Cáceres, en otra Badajoz y, más tarde, en 1230, Mérida, prometida una vez más a la iglesia del Apóstol, que mostró su interés en la conquista de la ciudad apareciendo en la batalla con otros muchos santos para derrotar a los musulmanes; el Apóstol defiende los derechos de su iglesia, y el “leonés» Isidoro

Sorprende el desmesurado elogio que Rodrigo Jiménez de Rada hace de la fundacion de Plasencia: "edifico de nuevo la ciudad de la gloria, constituyó en ella la defensa de la patria y lá llamo Plasencia, atrajo pobladores a la nueva ciudad y elevó ésta a la dignidad episcopal...". 
los del reino pues también él interviene en la batalla y para que nadie dude de su participación, anuncia previamente en Zamora «que acudiría con un ejército de saritos, que recuperaria la ciudad y obtendría un gran triunfo sobre los musulmanes". La ciudad fue conquistada y el prelado compostelano puso en ella como obispo a un hombre de confianza al que no tardó en destituir para en adelante evitar la peligrosa presencia de un obispo en Mérida entregando la ciudad a la Orden de Santiago, cuyos maestres seguirán siendo canónigos de Compostela y arcedianos de Reina, arcedianato estudiado por Francisco Javier Pérez en la tesis doctoral citada en páginas anteriores.

Los Estudios de Palencia y de Salamanca. Aparentemente, poco o nada tienen que ver las nacientes "universidades" de Palencia y de Salamanca con las tensiones entre Castilla y León, pero si tenemos en cuenta que Palencia es castellana y sufragánea de Toledo, y Salamanca leonesa-compostelana podremos entender el entusiasmo o el silencio con el que saludan los cronistas la creación de uno y otro Estudio. El Toledano nada dice sobre la creación de la universidad de Salamanca por Alfonso IX mientras se detiene en la fundación palentina de Alfonso VIII: "llamó a sabios de las Galias y de Italia para que la ciencia no estuviera ausente de su reino y reunió en Palencia maestros de todas las facultades a los que pagó espléndidamente para que la ciencia de cualquier facultad cayera sobre el que la deseara como el maná en la boca. $Y$ aunque el Estudio fue interrumpido, por la gracia de Dios todavia se conserva en el dia de hoy" ".

Por su parte, Lucas de Tuy, destaca sobre la intervención del rey la participación del obispo y del cabildo de Palencia: "el rey Alfonso llamó a maestros en teologia y otras artes liberales y creó escuelas, procurándolo asi Tello, obispo de la ciudad pues como quiere la tradición allí siempre se cultivó la ciencia escolástica" ". La referencia salmantina es breve: tras el primer ataque a Cáceres, "con saludable consejo llamó a maestros peritísimos en las sagradas escrituras y ordeno crear las escuelas de Salamanca y desde aquel dia es más directa la salud de la victoria en su mano", palabras que Juan Gil traduce casi literalmente

Llama la atención que Alfonso $X$. siguiendo al Toledano, nada diga de la creación de la Universidad de Salamanca de la que fue ilustre protector.

Aunque no se establece ninguna relación de causa a efecto, no estará de más llamar la atencion sobre el hecho que refiere Lucas de Tuy inmediatamente despues de hablar de la universidad palentina: “Este Rey Alfonso fue el primero que pintó un castillo en sus armas rompiendo asi la costumbre de sus antecesores que habian acostumbrado pintar un león por considerar que el león era el rey de todos los animales". el simbolısmo nacionalista del castillo frente al león es innegable como lo es el carácter nacional castellano del Estudio palentino. 
aunque dándoles un matiz bélico que Lucas de Tuy apenas insinúa: "apenas hubo momentos en los que no hubiera guerras y devastaciones entre los reyes; y aunque estuvo amenazado por todos los reyes vecinos, sin embargo Dios siempre estuvo con él, y para que le ayudara aún más, ordenó constituir con sus propias rentas un estudio general en Salamanca, y a partir de entonces tuvo en sus manos más directamente la salud de la victoria" ".

El historiador de las universidades medievales hispánicas, Vicente Beltrán de Heredia, llega a equiparar Palencia con Toledo en diversas ocasiones: "esta iglesia -Palencia- donde durante la ocupación de Toledo y su diócesis por los mahometanos solían celebrarse los concilios provinciales, estuvo gobernada por altas personalidades haciendo las veces de metropolitana...; dado el carácter de metropolitana que tenía de hecho la iglesia palentina, su escuela podían frecuentarla todos los naturales de la provincia eclesiástica de Toledo", aun después de liberada la capital del dominio sarraceno... Pese al esfuerzo del prelado palentino por afianzar la Academia, ésta fue perdiendo su vigor y al desaparecer él hacia 1240 y luego en 1247 el arzobispo don Rodrigo, quienes más se habian desvelado por su florecimiento...", " la escuela palentina fue languideciendo hasta desaparecer.

La vinculación salmantino-compostelana tampoco ofrece dudas a Beltrán de Heredia: "el ejemplo de Compostela cundió quizá más que en el resto de Galicia en otras iglesias del reino situadas fuera de aquella región, si bien dentro de la provincia eclesiástica. Las que más se beneficiaron de esta irradiación cultural fueron Zamora, León y sobre todo Salamanca... El elemento docente de la Universidad lo formaba el clero culto de Salamanca...; los puestos de mayor categoria del cabildo estaban ocupados por personal oriundo de Galicia, sobre todo de Compostela...

La relación Estudio Milicia figura en el texto de Lucas de Tuy de manera encubierta: tras narrar la creación del Estudio recuerda que en Palencia floreció siempre la sabiduria y anade: viguit et militia

Rodrigo no menciona para nada el territorio toledano y se limita a destacar el interés del monarca castellano en proteger la ciencia en su reino: Altonso $X$ supera el ámbito nacional y pasa de él al hispánico al tiempo que establece de manera directa una estrecha relación entre Estudio y Milicia: "ca por las escuelas de los saberes mucho enderesça Dios et aprovecha en el fecho de la cavalleria del regno do ellas son... el tomo maestros de todas las sçiencias et ayuntolos en Palençia, logar a abte et plantio pora venir los clerigos de todas las Espanras... (Primera Crónica General de España que mandó componer Alfonso el Sabio y se continuaba bajo Sancho IV en 1289 ", publicada por Menendez Pidal. Ramón. II. Madrid 1955, pág. 686).

Cartulario de la Universidad de Salamanca (1218-1600). Universidad de Salamanca 1970. págs. $41-43$ 
luego el elemento gallego preferentemente compostelano que forma parte del cabildo salmantino era el más indicado para hacerse cargo de las cátedras universitarias...; por formar los compostelanos un grupo compacto y tener en su favor el apoyo de los prelados que se suceden en la sede catedralicia, son ellos también los que logran los mejores puestos y procuran transmitirlos a sus coterráneos, parientes y allegados" " ${ }^{24}$ a veces mediante el simple procedimiento de nombrar desde la archidiócesis compostelana a los miembros del cabilcio salmantino cuando real o supuestamente los cargos permanecian vacantes durante un tiempo determidado $\%$.

\section{LA SUCESIÓN DE ALFONSO IX}

Los dos matrimonios de Alfonso IX complican la sucesión en el reino leonés a la muerte en 1230 del monarca, que deja como herederas a Dulce y Sancha, hijas de Alfonso y Teresa de Portugal, bajo cuya dirección el reino leonés debería mantenerse independiente de Castilla donde desde 1217 reinaba Fernando III, el hijo de Alfonso IX y Berenguela, jurado como heredero por los nobles y ciudadanos de León en tiempos de amistad $y$ alianza entre padre e hijo.

Los tres cronistas parecen favorables a la unión de los reinos y por tanto a la solución dada a la herencia de Alfonso; Rodrigo Jiménez de Rada y Juan Gil, siguiendo al pie de la letra al arzobispo, atribuyen todo el mérito a la reina Berenguela que supo mediar entre las partes, convencer a las infantas y a su madre para que renunciaran a sus derechos y a Fernando III para que fuera generoso con ellas y las dotara magnánimamente mientras vivieran. y sólo de pasada habla de la oposición a Fernando en tierras leonesas: "tras algunos enfrentamientos, Berenguela..."; por su parte, Lucas de Tuy concede más importancia y detalla los enfrentamientos habidos: hubo grandes alteraciones en el reino leonés; muchos nobles gallegos y asturianos incendiaron las poblaciones que carecian de murallas y se aprestaron a enfrentarse a Fernando, que contó con el apoyo del obispo y de los ciudadanos de León, armados para hacer

Ob. cit págs. 58-99. apartados sobre "Galicia en Salamanca durante la centuria decimatercia" y "Los catedráticos de la Uriversidad en el siglo xil|» cuyas conclusiones no dejan lugar a dudas: Ios puestos de más relieve en el cábildo salmantino durante aquel siglo los ocupaba personal oriundo de Galicia... Luego este mismo personal era el preferido para el desempeno de las cátedras..." (pág. 99)

Sobre este aspecto vease la bula de Urbano IV - 1 de marzo de 1262 - publicada por Belitian de Heredia. Bulario de la Universidad de Salamanca. 1. 1966, pág. 325 
frente al noble don Diego que habia ocupado, contra Fernando, la iglesia y torre de San Isidoro de León. Ahora, Dios interviene en favor de la unidad de castellanos y leoneses, en este caso enviando una grave enfermedad al noble, que oye voces en su interior según las cuales San Isidoro amenazaba con darle muerte por haber profanado su casa y oponerse al rey Fernando; las voces van acompañadas de hinchazón de los ojos, que, dolorosamente, parecían querer salirse de las órbitas, y, aterrado, Diego abandonó iglesia y torre, se hizo cargo de los daños causados y se comprometió a ser fiel vasallo de San Isidoro y de su protegido Fernando. Libres de la presión nobiliaria, obispo y ciudadanos llamaron a Fernando y le hicieron entrega de la ciudad capital del reino, entrega a la que el monarca correspondió confirmando sus buenos fueros. usos y costumbres y perdonando diversos gravámenes.

El decidido papel de la iglesia en favor de la unidad de ambos reinos es destacado también por Rodrigo Jiménez de Rada al hablar del reinado de Fernando III: Ia revuelta que preparan las hermanas del rey es neutralizada gracias a los prelados del reino y a los ciudadanos que, inmediatamente después de la muerte de Alfonso, se adhirieron a la causa de Fernando e impidieron el triunto de la revuelta y llevaron a Teresa de Portugal a buscar la negociación con Berenguela de Castilla; puestas de acuerdo las esposas de Alforiso IX en Coyanza, dias más tarde se reunian en Benavente y confirmaban el acuerdo las infantas Dulce y Sancha y su hermano Fernando que desde entonces es llamado rey de Castilla y León, a pesar de lo cual leoneses y castellanos recordarán durante años la separación de los reinos y la reflejarán en crónicas como las escritas por Rodrigo Jiménez de Rada, Lucas de Tuy o Juan Gil de Zamora.

\section{APÉNDICE}

\section{El reinado de Alfonso IX en las cronicas}

1. Mortuo rege Fernando successit ei filius eius Aldefonsus. Hic fuit homo pius strenuus et benignus, sed susurronum vicissitudine mutabatur et a consobrino suo Aldefonso Rege Castellae et Sancio Rege Portugalliae infestatus circa principum regni sui venit ad Regem Castellae et in curia Carrionis accinctus ab eo cingulo militari, manum eius fuit in plena curia osculatus.

Et sic tempus quievit terra. pace amicabiliter reformata. Sed quia, ut diximus, auriculariorum susurris ad varia trahebatur. eorum consilio duxit Tarasiam. filiam Sancii

En cursiva figura el texto de Lucas de Tuy: en negrita el de Juan Gill de Zamora. 
Regis Portugalliae. in uxorem, licet essent consanguinei in secundo gradu... Et in odium Regis Castellae fuit hoc contubernium procuratum: suggerentibus enim suis vernulis. dolebat se a Rege Castellae recepisse cingulum militare, et tamen ab illa uxore fuit iudicio ecclesie separatus

Era MCCXXVI. mortuo Rege Femando, fllius eius Adefonsus successit et in reg num Legionense. Hic fuit pvicher. eloquens, clemens. fortis viribus et armis strenuus et in flde Catholica solidatus. tamen in primordio regni sui inquietatus fuit valde a collateralibus suis scilicet ab avunculo suo Sancio Rege de Portugalia et ab Ade fonso Rege Castellae consobrino suo. Unde compulsus ducere in uxorem Tharasiam filiam eiusdem Regis Sancii. ut ipsum Regem Sancium haberet in auxilium contra Adefonsum Flegem Castellae. Ex ista Tharasia genuit tres filios...

Suprafatus autem Adefonsus Rex Legionensis ex quo regnare coepit regnum sibi subditum viriliter et nobiliter vendicavit et tam terribilis fuit male agentibus, quod suum aspectum non possent aliquatenus sustinere. Vox eius in ira quasi leo rugiens videba. tur. Cum esset indutus armis bellicis et equum suum conscenderet. licet mag nus esset motus corporis. quidam tamen gestus in eo nimiae ferocitatis fortitudinem in eius animo declarabat Hic in bello nunquam fuit victus. sed victor semper exVtit quamvis multoties cum Christianis et Sarracenis pugnavit. Hanc suam fortitudinem etiam clementia sequebatur ut iram statim a corde excuderet et misericorditer flecte fena deponens virus quod susurrones suis auribus instillaverant si esset qui diceret bonum...

Circa viros religiosos et moniales adeo misericoris fuit ut quando illis deerat praeberet de suis cellariis alimenta: gregesque omnes pecudum quae illi de hostium praeda eveniebant cunctis monasteriis distribuebantur. Latrones autem et superbos alios a turribus praecipitabat, alios in mari mergebat, alios suspendebat, alios igne cremabat. alios caldariis decoquebat, alios vivos excoriabat et multis ofliciebat ge neris tormentorum ut regnum in pace et iustitia conservaret.

Fecit eVam largissimus Rex quoddan memoria dignum pre regibus qui fuerunt ante ipsum nam adiuravit omnes iudices regni sui ut non acciperent ab aliquo parvum vel magnum donum. Ipse quidem eis de suo aerario omnes abundanter faciebat expensas ne iudices propte; dona perverterent iudicium ef iustitia haberetur venalis...

Aldephonsus decimus, tertius fuit tilius regis Fernandi, regis Legionis, qui obiit Benaventi, era millesima ducentisima vigesima octava; cuius Fernandi avus tuit Comes Raymundus. Hic Adephonsus successit patri suo regi Fernando in regno I.egionis et tuit quasi coevus in regnando cum Adephonso, nobili rege Castelle, qui obtinuit in prelio Ubetam.

Prefatus igitur rex Aldephonsus luit rex pulcher, eloquens, piu8, strenuus et benignus, simplex, hilaris, magnanimus, liberalis, in omnibus preliis inde victus et absque auxilio alienigenarum gentium sempe victor. Verumtamen, sicut imponeabur sibi ab emulis convicinis, propter sui simplicitatem nimiam susuronum vicissitudine mutabatur; et a consobrino suo Aldephonso, rege Cas telle, et Sancio Rege Portugalie, infestatus, circa primordia regni sui venit ad Regem Castelle, et in curia Carrionis fuit accinctus cingulo militari...

Et sic ad tempus quievit terra, pace amicabiliter reformata; sed intervenien tibus auriculariorum susurriis et maledicis, Aldephonsus, eorum consilio, duxit Tarasiam filiam Sancii regis Portugalie, in uxorem, licet essent consanguinei in secundo gradu... et in odium Regis Castelle fuit hoc contubernium precatum, suggerentibus enim suis nonnullis, dolebat se a 


\section{Rege Castelle recepisse cin gulum militare; et tamen ab illa uxore fuit iuditio ecclesie separatus...}

Fuit autem tante iustitie quod omnes regni sui iudices adjuravit ne donaria vel exenia reciperent, que claudunt vel excecant oculos magnatorum; ipsis autem iudicibus de thesauris regiis providebat...

2. Demum inte ipsum et Regem Castellae guerris et vastationibus perpetratis duxit uxorem dominam Verengariam Regis Castelle filiam... et suscepit in ea filios, Fernandum cui Castellae et Legionis provenit postea principatus. et Aldefonsum et duas filias

Rex autem Aldefonsus et Regina Verengaria, susceptis filiis supradictis, propter consanguinitatem fuerunt ab Innocentio Papa tertio separati. Et postea inter Reges guerrae et vastationes vix aliquo tempore cessaverunt. Rege Tamen Castellae in omnibus prevalente, et de regno alterius castra et plurima occupante: sed tamen nec sibi nec filio sed nepoti Fernando omnia acquirebat.

Rex autem Castellae cum exercitu suo Regi Miramamolino obviam properavit Veniebat quoque Adefonsus Rex Legionis in auxilium Regis Castellae cum exercit magno. sed Rex Castellae bellandi animositate incensus noluit eum expectare, lice Rex Legionensis cum exercitu suo properans iam esset Toleti... Habuit tunc Rex Castelle pacem cum Chris Vanis et Sarracenis, sed illatum sibi a barbaris dedecus ab eius animo non recedebat Tamen dum Sanclus Rex Navarre contra ipsum moveret praelium una cum Adefonso Legionensi Rege. Rex Castellae fines Navarrae invasit... Post haec etiam habuit discordiam cum Rege Adefonso Legionensi et cepit castrum Ardon et Coiancam. Castrumviride et quaedam alia. Post haec venit usque Legionem et cepit casta ludaeorum iuxta ipsam civitatem. Obsedit etiam Astoricam sed non cepit eam. Accessit ad submontanam ad castrum quod dicitur Alva et cepit illud. Rex autem legionis Adefonsus occurrit ei cum magno exercitu ad ipsum locum ut pugnaret cum eo. Sed Petrus fernandi de Castella. qui tunc erat cum Rege Legio nensi et alii viri Deum timentes reformaveruntpacem inter Regem Castellae et Regem Legionis.

Cum autem pax esset inter eos, quidam inimici Dei discordiam seminantes iterum inter eos bellum concitaverunt et per tres continuos annos inter se fortissimorum regum exercitus horriferis gladiis confligebant. Multae perpetrabantur hinc inde cae des hominum praecedebat; quod in agris erat ef flammis villae exurebantur. Praeibat Regem Castellae fortitudo et sapientia, sed Regem Legionis fortitudo et suorum exercitum amabilitas nimia muniebat.

Sed antequam inter dictos Reges tam honibile oriretur bellum. ostendit Dominus quoddam prodigium in ecclesia Sancti Stephani extra muros urbis Legionis. Etenim quaedam imago Dei genitricis cum imagine fill sui ex se coepit emittere sanguinem. non sine horrore et admiratione multorum. qui hoc viderunt Tunc clerus et populus Legionis ad praedictam ecclesiam accesserunt pedibus nudis, et ipsam imaginem ad ecclesiam beati Isidori detulerunt et super ipsius altare posuerunt ubi per tres dies continuos sanguinem emanavit Sed fuerunt quidam sapientes interpretes, qui ex ipso signo bellum futurum cruentissimum praedixerunt eiusdem monasterii ex haeredationem etiam praedicentes. Quod postea factum esse testatur veritas ma nifesta.

Etenim, ut praediximus, bellum cruentissimum inter Reges exortum est et tradente Legionensi Rex Castellae castrum de Pozolo accepit. qui iam acceperat villam Barxeni. Caparios et alia plura ad ecclesiam beati Isidori spectantia, ex quibus svstentabantur clerici inibi domino servientes. Adefonsus Rex Legionis, cum esset catholicus, habebat 
secum clericos qui modulatis vocibus quotidie coram ipso divinum officium peragebant quos ipse nimio venerabatut affectu. Habebatque cubicularios suos laicos quosdam quibus omne consilium suum committebat et licet polleret omnimoda probitate, tamen susurronibus aliquando praebebat aurem. Unde quae dam faciebat minus spectantia ad tam regiam maiestatem. Rex autem Castellae, cum esset sapientissimus, consilium suum semper sapientibus committebat unde caeteris Hispaniae Regibus feliciores habebat successus.

Pacificatum est inter Reges preadictos post multas strages et damna, sed iterum inter eos mora discordia cum venirent ad pacem dedit Rex Adefonsus legionensis uxori suae Reginae dominae Berengariae queae tunc degebat cum patre suo in Castella Villaparpandum. Ardon. Rodam. Arbolium. Gordonem et Lunam..

Hic ex sententia domini Pape Innocencii. dimissa uxore sua Regina Tharasia, duxit Berengariam prudentissiman filiam Adefonsi Regis Castellae uxorem et tam nobiliter eam desponsavit sibi quod dedit ei prodote turres Legionis. Astoricam. Valenciam et alia triginta castella. Posuit etiam in fidelitate alia decem castella in manu baronum Regis Castellae. ne recederet a pactione.

Genuit ex ista Berengaria Fernandum. Adefonsum. Alionaram. primogenitam. Constantiam et Berengariam...

Flex autem Adefonsus (Castellae) cum esset in angustiis positus eo quod bara baris commode non poterat obviare. convocavit Regem Aragonae ef regem Navanae. precibus et mnueribus, ut secum accederent contra barbaros pro fide catholica pugnaturi. Misit etiam idoneos nuncios ad regem legionensem ut ipse quoque dig naretur tanto periculo subvenire. Sed Rex Legionensis licet ad subveniendum de sideraret accedere, tamen. habito cum suis consilio respondit quod libenter acce deret si Rex Castellae sibi redderet castra quae illi abstulerat. Rex vero Castellae cum esset erga plurima occupatus et in arcto positus non potuit ad singula res pondere sed totum animi sui impetum direxit ad iniurias sibi a Sarracenis illatas omnimode vindicandas...

Cum auem haec agerentur. Rex Legionensis Adefonsus habebat secum virum potetissimum Petrum Fedinandi de Castella, qui ei nobiliter consilum et auxilium impendebat. et ipso dicto Petro Ferdinandi operam dante recuperavit de illis oppidis quae sibi abstulerat Rex Castellae Rodam. Ardon. Castrumterram. Villalugam. Cas trum Gorizalvi. Albalista. Lunam. Gordon. Arvolium. Alion et quaedam alia. Intulit quoque Adefonsus Rex Legionensis bellum Portugalie et cepit Balsamon. Ulgosum. Fresno et ex alia parte Lanosum. Melgazon et Contrastam qua funditus diruit Tunc congregati surt contra ipsum omnes Portugalenses ad praelium et licet esset Rex Legionensis cum paucis. vicit eos in loco qui dicitur Portella de Valdever et cum multis spoliis et gloria reversus est.

Rex autem Castellae Adefonsus. qui post felicem victoriam timebatur venire super Legionenses in ira et brachio extento, valde humilis venit laudans Deum de victoria reddita populo Christiano et invitans ad pacem Regem Legionis indulsit el omnia oppida que abstulerat sibi et insuper restituit ei Pennamfiel. Almazan et collem in terra Legionis et in Asturiis Mirandam de Nicua et in territorio Salmantiae dedit sibi ad diruendum castellum de Carpio et Montemregalem. Rex etiam Legionis ex pacto Regis Castellae tradidit Regi Portugaliae omnia castra quae abstulerat illi. Hoc Rex sapientissimus Castellae ideo faciebat ut paciflcatis ominubs Hispaniae Regibus eos contra Sarracenos concitaret. 
Tunc Rex Adefonsus destruxit Gordonem et Arbolim ut Legionensis civitas se curitate frueretur et pace. lam olim destruxerat ludaeorum castrum iuxta Legionem Alfonso IX y sus relaciones con Castilla quia eidem civitati multa damna saepius inferebat Destruxit etiam Miraventum iuxta Maioricam.

Et accepto a Rege Castellae in auxilium sui potestissimo viro Didaco Lupi sumpsit arma contra Sanacenos et obsedit Alcantaran et cepit eam. Eo tempore mortuus est Femandus, filius eius pulcherrimus adolescens, quem genuerat ex Regina Tharasia et sepultus est in Ecclesia Sancti lacobi Apostoli. De cuius morte valde doluit Le gionensis Rex et regnum eius..

Demum inter ipsum et regem Castelle guerris et vastationnibus perpetratis, duxit uxorem dominam Berengariam, regis Castelle filiam; et suscepit ex ea filios Ferdinandum scilicet cui Castelle et Legionis pervenit postea principatus, et Adephonsum et duas filias...

Antea vero quam inter prefatos reges bellum tam sevissimum oriretur, in ecclesia Sancti Stephani extra muros urbis regie Legionis imago beate Virginis cum imagine sue prolis sanguinem emiserunt; ad cuius admirandum specta culum tam clerus quam populus convenerunt et ad ecclesiam beati Isidori pro cessionaliter et nudis pedibus predictam imaginem detulerunt, ubi supra ipsum altare per tres dies continuos, cunctis spectantibus et admirantibus, sanguinem emanavit in signum tanti sanguinis efundendi...

Rex autem Aldephonsus et Regina Berengaria, susceptis filiis supradictis, propter consanguinitatem fuerunt ab Innocentio papa tertio, separati; et postea inter reges guerre et vastationnes vix aliquo tempore cessaverunt; et cum in festaretur ab omnibus regibus convicinis, semper Dominus adiuvavit eum, et ut amplius adiuvaret, apud Salmanticam generale studium de reditibus propriis ordinavit; et ex tunc magis directa fuis salus victorie in manu eius.

3. Verum in senectute positus Rex Legionis, actus suos Domino dedicavit et Arabibus movit guerram et obtinuit ab eis Montemangii. Emeritam. Badallocium, Alcantaram, atque Canceres.

Et reliquit duas filias. Sanciam atque Dulcem quibus etiam successionem regni legavit. Sed quia omnes regni nobiles tam de civibus quam de aliis olim filio suo Fernando iuraverant. non potuerunt regnum filiae obtinere. Sed aliquantis discidiis procuratis, et civitatibus et nobilibus in varia studia separatis, nobilis Verengaria Regina Castellae interposuit artes suas et sic omnes gratiae sollertia dulcoravit quod licet Infantes quamplurimos fautores haberent et munitiones et castra quamplurima in omnibus fere regni finibus possiderent. ad hoc. Infantes et matrem eorum Reginam Tarasiam necessitate induxit ut eius gratiae se sponderent Unde paterne largitatis in omnibus imitatrix, curialitate sua, ut Infantibus quoad viverent, magnos reditus fecit a filio assignai et sic obtinuit pacifice regnum patris aera MCCLXVIII.

Era M CCLV Fernandus. tilius Adefonsi Regis Legionensis in Castella, ei matre Berengaria tradente regnum. felicissime regnare coepit...

Sed cum regnare coepisset comes Alvarus de Castella et tratres eius Comes FeMandus et comes Gundisalvus contra eum rebellare coeperunt... Rex autem Le gionensis Adefonsus cum exercitu svo quosdam regni Castelle fines molestabat eo quod adhuc quaedam ad regnum Legionense spectantia retinebant Castellani. Tunc. congregaV sunt contra eum omnes nobiles de Castella quia revera filius eius rex 
Femandus cum patre pugnare nolebat. Inito autem certamine praedicti nobiles Cas telle fugati sunt et omnes in Castellon a Rege Adefonso infusi. Tunc mutuo collo quentes de pace. ut iustum erat. firmaverunt pacem inter patrem et filium et ad tantam concordiam regna Hispaniae pervenerunt ut unanimiter convenirent ad Arabes per sequendos. O quam beata tempora...

Adefonsus Rex Legionis. ubl cum fllio suo pacem habuit. quosdam rebelles in regno suo perdomuit. Rege Fernando filio suo auxilium praebente; et congregato exercitu magno contra Sarracenos arma movit; et cuncta que erant in circuitu de Caceres. scilicet arbores. vineas et segetes ferro et flamma vastavit et ad propia reversus est. Hic salutari consilio evocavit magistros peritıssimos in sacris scripturis et constituit scholas fieri Salmantinae et ab illa die magis direcla est Victoriae salus in manu eius...

Rex Adefonsus iterum cum magno exercitu terram Maurorum ingresus cuncta quae erant in circuitu de Badaioz exterminavit... Post haec Reverendissimus pater loannes Cardinalis Romanus Sabiniensis Episcopus. Apostolice sedis legatus, missus est in Hispaniam a gloriosissimo Papa Gregorio. Hic inter caetera quae sanctae gessit Reges Hispanos contra Sarracenos studuit incitare. unde Rex Legionensis Adefonsus cum exercitu suo et parte exercitus filii sui Regis Fernandi obsedit Ca ceres, oppidum fortissimum barbarorum et cepit ipsum.

Filius autem eius Rex Castellae Femandus ingressus est terram Maurorum cum exercitu magno... Sequenti veo anno Adefonsus Rex Legionensis obsedit civitatem Emeritam et cepit eam. Erat tunc temporis quidam barbarus insignis nomine Abentuth qui expulsitAlmophades ab Hispania et factus est Rex barbarorum. Hic a suis vocatur Rex virtutis et congregato exercitu Maurorum innumerabili venit pugnaturus cum Ade fonso Rege Legionensi qui erat Emeritae cum paucis. Sed Rex Adefonsus, ut erat fortis et animosus, fecit exercitum suum de nocte contra Sarracenos flumen Gua dianam transire. Fixerant Sarraceni tentoria iuxta castrum Alhange et viderunt primo mane nostrorum acies paratas ad bellum et ipsi ordinaverunt acies suas ad praelium properantes. Fuit Dominus cum Rege Adefonso et populo Christiano et in congres siones ipsius belli tanta Sarracenorum millia postrata sunt quod multa barbarorum oppida remanserunt vacua omnibus habitatoribus eorum extinctis in ipso bello... Tunc Rex Adefonsus a victoria reversus obsedit Badaiozum et post paucos dies cepit ipsum. Dimiserant Sarraceni Eives et castra alia plura se fugae committentes, quae Christiani populaverunt cum vacua recepissent Reversus est Rex Adefonsus cum multis spoliis et victoria magna laudans Deum et beatum lacobum qui sibi de inimicis dedit tam nobiliter triumphare. Siquidem in ipso bello visibiliter apparuit B. lacobus cum multitudine milium alhatorum qui Sarracenos in manu valida prosternebant Beatus etiam Confessor Isidorus quibusdam apparuit Zemore ante quam Emerita ca peretur et bellum fieret et dixis eis se ad auxilium Adefonsi Regis cum Sanctorum exercitu properare et quod sibi dictam traderet civitatem et de Sarracenis compalem praeberet triumphum.

Rex autem Fernandus, filius eius. tunc temporis erat in expedivone in terra Maurorum et cum audisset quod decesserat pater eius, festinavit venire Legionem ut obiineret regnum patrum sourum. Eo tempore facta est perturbatio magna in regno Legionensi. Multi namque milites Galleci et Astures multas populationes quas Rex Adefonsus fecerat absque murorum ambitu, incendio tradiderunt. Nitebantur etiam resistere Regi FeMando si possent. sed omnipotens Deus illum mirabiliter adiuvavit Etenim miles nobilissimus Didacus cum esset Legiones fecit suos per palatium Regis fwtive ascendere et turrim et eclesiam beati Isidor occupavit Reverendus autem pater Rodericus Episcopus Legionensis vir nobilis, probidus et honestus, ut haec vidit. 
Ecclesiam Legionensis Sedis armis, hominibus et bellicis apparatibus munivit, ut civitas Regi Femando servaretur. Civesque turres murorum ef ecclesiarum. un potuerunt similiter munierunt. Erat tunc in ipsa civitate, die ac nocie. continua vox belli ef tribulatio et angustia magna. Sed misericordia Dei non defuit et praedictus Didacus aegritudine valida est percussus ita ut ipse vel in eo. nescio quis clamaret. quod beatus Isidorus ob auxilium Regis Femandi volebat ipsum militem interflcere eo quod occupaverat turrim et Ecclesiam eius. Praeterea a capite dicti militis oculi videbantur avelli et a concavitate sua egrediebantur non sine magno dolore. Unde compulsus. cum se videret tam gravissime vexari, consilio Sanciae Comitissae ve nerabilis matris suae, abbati et conventui ipsius monasterii turrem et ecclesiam res tituit et damna quae illis intulerat, integravit dato super sancta Dei Evangelia iura mento quod de cetero esset miles et vassallus beaV Isidori Confessoris. Illico sanitati restitutus est et statim cum suis de civitate egressus

Episcopus autem Rodericus et cives, gaudentes in Domino quod etiam sancti pro Rege Fredenando pugnabant. Miserunt nuncios illi venire! cito suam accipere civitatem. Venit itaque Rex Fernandus, qui vere creditur Rex virtutis eo quod sit virtuosus, una cum prudentissima Domina Berengaria matre sua et Legionensem civitatem ingressus, cum gloria magna obtinuit regnum patrum suorum. Tunc, con fluentibus ad eum de singulis civitatibus et oppidis viris nobilissimis concessit eis bonos mores et foros antiquos et etiam illis multa gravamina relevavit.

Supererant duae nobilissimae sorores suae, filiae Regis Adefonsi, quas genuerat ex Regina Tharasia. Sancia scilicet et Dulcia. quas habuit in magna reverentia donans illis dum viverent, annuaVm triginta millia aureorum. Deinde pacificato toto regno suo. omnes milites qui populationes patris sui succenderant exulavit

Alphonsus vero prefatus rex inclitus Legionis, in veneranda senectute po situs, actus suos Domino dedicavit et arabibus movit guerram et obtinuit ab eis Montanches, Emeritam, Badallocium, Alcantarm atque Caceres...

Cum autem Rex inclitus Aldephonsus transiret ultra flumen Guadianam ut Avenphut barabarorum regem strenuissimum expugnaret, contigit quod alterum ex calcaribus de ipsius pede cecidit, fibula dissoluta; ad quod factum cum circunstantes non modicum conturbati colloquerentur intra se murmure que ruloso, audita causa murmurationis, Rex strenuissimus sic respondit: Certe non decet regem nobilem cum calcoribus, tanquam formidolosus, bellum ingredi; et ideo calcar cecidit, ut et aluid calcar dimitterem tanquam non credens fugere. sed potius insistens actibus bellicis superare. Quod et accidit nam Abenphut fugit de prelio graviter vulneratus et de sarracenis plusquam triginta milia, ut creditur, co rruerunt. Apparuit autem Beatus lacobus in illo prelio cum multis militibus can didatis, prosternentes Arabes hind et inde. Beatus etiam Confessor Isidorus Zamore quibusdam apparuit antequam Emeritensis civitas caperetur et dixit se ad regis Aldefonsi auxilium cum Sanctorum exercitu properare, ut sibi traderet civitatem et de sarracenis triumphalem victoriam obtineret...

Et reliquit duas filias, Sanciam atque Dulcem, quibus etiam successionem regni legavit; sed quia omnes regni nobiles tam de civibus quam de aliis, olim filio Fernando iuraverant, non potuerunt regnum filie obtinere; sed aliquantis discidiis procuratis, et civitatibus et nobilibus in varia studia reparata, nobilis Berengaria regina Castelle interposuit partes suas et sic omnes gratie solertia dulcoravit, quod licet filie Regis Infantes quamplurimos factores haberent et 


\section{munitiones et castra quamplurima in omnibus fere regni finibus possiderent, ad hoc Infantes et matrem earum Reginam Tharasiam necessitas induxit ut eius gra- tie se sponderent; verum paterne largitatis in omnibus imatitrix, curialitate sua, Infantibus quoad viverent, magnos reditus fecit a filio assignari; et sic obtinuit Rex Fernandus pacifice regnum era MCCLXVIII.}

A los parrafos de Rodrigo Jiménez de Rada hay que añadir las páginas que el arzobispo de Toledo dedica al rey leonés cuando traza la historia de Altonso VIII de Castilla:

Nunc ad Aldefonsi Regis historiam revertamur, escribe tras contar como Beren guela puso fin a las ambiciones de Sancha y Dulce. Licet igitur fidelitate suorum regni perdita reparasset, tamen semper fuit a patruo infestatus

Cuando habla de la batalla de Alarcos, indica: Cum autem Aldefonsus Rex Le gionis et Sancius Rex Navarre venire in auxilium ad bellum Alarcuris simulassent et iam ad regni Castellae confinia pervenisset, audito quod in predicto bello non bene succeserat, a proposito destiterunt et Rex Navarre qui iam ad regnum Cas tellae pervenerat, retrocessit. Rex Legionis pervenit Toletum ubi paucis diebus cum Rege nobili commoratus. ad terram rediit Legionis et pos modicum temporis inter valum ambo hostiliter regnum Castellae hostiliter invaserunt. Sed Rex Legionis Ara bibus foedere sociatus. multis ex eis secum adscitis, regnum Castellae per campos Gothicos est ingressus, diruens, diripiens et desvastans... Rex autem nobilis Al defonsus foederato sibi fideli amico Petro Rege qui in Aragonia tunc regnabat, terram ingressus est Legionis et obtinuit plura castra. scilicet Bollanos, Vallem Area rum, Castrum viride, Coiancam (quae mutato nomine Valentia nuncupatur). Carpium et Paradinas. Et plurimis praeliis actis et caedibus perpetratis. effugatis etiam Aga renis quos Rex Legionis secum duxerat. ambo ad propria redierunt

Tunc temporis Rex Castellae et Rex Aragonum. contra Regem Legionis pariter processerunt et obtinuerunt castrum Legionis et Ardon et castrum Gundisalvi et castrum Terrae et Albam de Aiiste et usque ad Astoricam cuncta caedibus et in cendio vastaverunt: et inde per partes Alvae et Salmanticae venientes, omnia ex terminio consumpserunt. et Montem regalem. castrum nobile. occuparunt: inde ad propria remearunt. Sed Rex nobilis Aldefonsus dignum iudicans furori cedere ve nienti, ad tempus cum Rege Arabum fecit treguam. ut posset tutius vicinis Regibus obviare.

Cumque proponeret Regem Legionis truciori dispendio infestare, quidam guerrae periculum pavescentes, familiari consilio procurarunt, ut Rex Legionensis peteret a Rege Casteilae filiam suam Berengariam in uxorem... et Regi Legionis Vallem Oleti cum suis magnatibus venienti dedit praedictam filiam in uxorem, et propter nuptias datis donationibus quae tantae dominae competebant, et nuptiis sollemniter cele bratis, traduxit eam in regnum suun. Rex autem Castellae nobilis Aldefonsus omnia quae abstulerat, nunc geriero, olim hosti, dedit filiae suae nuptae. Et sic pace quasi cum filio reformata, a vastationibus quieverunt

Con su yerno. Alfonso VIII ataca más tarde el reino de Navarra: Rex nobilis Aldetonsus iniuriam impatiens, adscito sibi genero suo Rege Legionis, fines in gressus est Navarrorum... Postea autem inter Regem Castellae et Regem Navarrae et Regem Legionis tregua per irtervallum temporis intervenit..

Para nada aparecen Alfonso IX y los leoneses en la batalla de Las Navas de Tolosa. e indirectamente Rodrigo señala la ausencia y los ataques de Alfonso IX a Castilla: Rex nobilis ab ascensionibus corde conceptis non potuit retineri et cum 
Aldefonso Rege Legionensi, olim genero, foedus initum innovavit et restituit ei Rex Castellae Carpium et Montem Regalem. ut diruta de cetero non starent. Et dato ei in auxilium Didacto Lupi de Pharo, magnate nobili et potente. Reges pariter con dixerunt ut uterque per confinia regni sui exercitum duceret contra Mauros; et Rex Legionensis in eo introitu cepit Alcantaram. munitionem nobilem. quam dedit postea fratribus Calatravae.

La sucesion de Alfonso IX ocupa amplio espacio en el relato del arzobispo de Toledo: ... rumor advenit patrem suum.. ab hoc seculo migravisse... ef quod etiam regnum legaverat. quas ex Regina Tarasia susceperat, filiabus Proter quod mater eius Regina nobilis domina Berengaria ad eum materna sollicitudine veniebat ut ad recipiendum regnum paternum quantocius festinaret. quod ei de mandato patris pontifices. magnates et civitatum concilia iurarant, ne forte in mora perturbatio ali qua oriretur... Indeque ad castrum Sancti Cypriani de Mozoth cum matre et comitatu veniens castrum ei ut domino reddiderunt. Sequenti die eum similiter in villa Lalii receperunt. ubi ad Regem. tamquam ad dominum, ex Tauro, riobilissimo oppido. milites advenerunt, qui Regem sui et oppidi naturalem dominum cognoverunt et. ut sequenti die Taurum adiret. instantissime suplicarunt. nobili Regina haec omnia procurante. Altera vero die Taurum intravimus ubi omnibus annuentibus. Rex Fer nandus, facto sibi hominio, in Regem et dominum est receptus. Indeque per castra dominae Reginae aliquandiu incedentes. recepimus ex aliis civitatibus milites et nuncios venientes. que videbantur de receptione Regis aliquantulum dubitare. So rores enim domini Regis. Sancia et Dulcia, de quibus diximus. rebelionem cum complicibus preaparabant. Sed tamen regni praelati, quorum interest regnum et sacerdocium contueri, in auditu auris Regem Fernadum in regem illico receperunt. scilicet lonannes ovetensis. Hi omnes cum suis civitatibus. patre mortuo. filio se dederunt, nec rebellio cogitata potuit invalere. Nam quam cito venimus Maioricam et Mansellam. Regi se protinus reddiderunt

Sequenti vero die intravimus Legionem, quae in regno illo sedis regiae praeminet dignitate, ibique ab Episcopo et universis civibus ad regni Legionis fastigium ele vatur, clero et populo Te Deum laudamus cantantibus concorditer et iucunde; et ex tunc Rex Castellae et Legionis pariter est vocatus.

Ibique nuncii advenerunt ex parte Reginae Tarasiae super compositione inter nuncia referentes. el licet verbum magnatibus displiceret, tamen Regina nobilis in tantum timult regni et pauperum vastationem. quod procuravit. ut Rex subsisteret Legioni, et ipsa iret Valentiam de concordia cum Regina Tarasia tractatura. Cumque ambae Reginae Valenciae convenissent, sic sollertia Reginae nobilis Berengariae procuravit, ut Regis sorores Regi restituerent omnia quae tenebant, et ipsae essent provisione contentae, quam eis Rex et Regina nobilis assignarent; si quid iuris in regno habebant. simpliciter resignarent.

El pacto huiusmodi confirmato, Rex advenit et inde omnes ivimus Beneventum. quo etiam Infantes filiae Reginae Tarasiae advenerunt, ubi Rex Fernandus et Regina nobilis eis reditus triginta millium aurerorum in locis competentibus assignarunt percipiendos toto tempore vitae suae 